\title{
Children's dental fear and anxiety: exploring family related factors
}

Lingli $\mathrm{Wu}^{1}$ and Xiaoli $\mathrm{GaO}^{2^{*}}$

\begin{abstract}
Background: Dental fear and anxiety (DFA) is a major issue affecting children's oral health and clinical management. This study investigates the association between children's DFA and family related factors, including parents' DFA, parenting styles, family structure (nuclear or single-parent family), and presence of siblings.

Methods: A total of 405 children (9-13 years old) and their parents were recruited from 3 elementary schools in Hong Kong. Child's demographic and family-related information was collected through a questionnaire. Parents' and child's DFA were measured by using the Corah Dental Anxiety Scale (CDAS) and Children Fear Survey ScheduleDental Subscale (CFSS-DS), respectively. Parenting styles were gauged by using the Parent Authority Questionnaire (PAQ).
\end{abstract}

Results: DFA was reported by $33.1 \%$ of children. The mean (SD) CFSS-DS score was 29.1 (11.0). Children with siblings tended to report DFA (37.0\% vs. 24.1\%; $p=0.034$ ) and had a higher CFSS-DS score (29.9 vs. 27.4; $p=0.025)$ as compared with their counterpart. Children from single-parent families had lower CFSS-DS score as compared with children from nuclear families ( $\beta=-9.177 ; p=0.029)$. Subgroup analysis showed a higher CFSS-DS score among boys with siblings $(\beta=7.130 ; p=0.010$ ) as compared with their counterpart; girls' from single-parent families had a lower CFSS-DS score $(\beta=-13.933 ; p=0.015)$ as compared with girls from nuclear families. Children's DFA was not associated with parents' DFA or parenting styles $(p>0.05)$.

Conclusions: Family structure (nuclear or single-parent family) and presence of siblings are significant determinants for children's DFA. Parental DFA and parenting style do not affect children's DFA significantly.

Keywords: Dental fear, Dental anxiety, Children, Parents, Parenting styles, Family factors

\section{Background}

Dental fear and dental anxiety (DFA) refer to the strong negative feelings associated with dental treatment, whether or not the criteria for a diagnosis of dental phobia are met [1]. The reported prevalence of DFA among children and adolescents in different countries ranged from 5 to 33\% [1-4]. Children with DFA often try all means to avoid or delay dental treatment, resulting in deterioration of their oral health [5]. They also demonstrate poor cooperation during dental visits, which compromises the treatment outcomes, creates occupational stress on dental staff, and causes discord between dental professionals and their parents [1]. DFA

\footnotetext{
* Correspondence: gaoxl@hku.hk

${ }^{2}$ Dental Public Health, Faculty of Dentistry, The University of Hong Kong, 3rd Floor, Prince Philip Dental Hospital, 34 Hospital Road, Sai Ying Pun, Hong Kong

Full list of author information is available at the end of the article
}

acquisition in childhood may track into adulthood and is a significant predictor for dental avoidance in adulthood $[6,7]$. Preventing and intercepting DFA during childhood is considered as a critical approach for improving people's oral health and dental experience [5].

It was speculated that parents' DFA might exerts an influence on their children's DFA through modeling and information [8]. Many adults with DFA may verbalize their fearful feelings in front of their children, creating a negative impression on dental treatment [5]. Most children at early school age begin to emulate their parents who are looked upon as models [9]. They are very likely to internalize their parents' values, attitudes and worldviews, which would gradually become a part of their own belief system [9]. There is moderate evidence to support the relationship between parental and child DFA [10]. An American study reported that over 40\% of

(c) The Author(s). 2018 Open Access This article is distributed under the terms of the Creative Commons Attribution 4.0 International License (http://creativecommons.org/licenses/by/4.0/), which permits unrestricted use, distribution, and 
parents/guardians gave their children negative connotation about their previous dental visit [11]. This study also showed a shared anxiety between parents/guardians and their children, thus suggesting that parents played a key role in children's anxiety and fear development. In another study, parental dental anxiety was demonstrated as a significant indicator for children's dental anxiety $(\beta=0.244 ; p=0.016)$ [12]. Despite the potential influence of parents, consensus is lacking regarding whether mother or father plays a more significant role in children's DFA. A previous study concluded that fathers deliver major information, such as danger, to children and play a mediating role for the transfer of dental fear from parents to children [13]. However, another study showed no significant difference between the influence of mothers and fathers on their children's DFA [14].

Parenting styles provided an environmental framework for children's psychosocial growth and were assumed to shape children's behaviors [15]. Baumrind identified three main styles of parenting, namely authoritative, authoritarian, and permissive [16]. This classification of parenting styles has served as a useful tool for investigating the influence of parenting on various issues concerning child development [16]. The relationship between parenting styles and children's dental fear has attracted some scholarly attention. A study measured parents' child-rearing attitudes and found that the subscale self-complaints (example item "My child's happiness needs a lot of sacrifice on my part") were associated with children's dental fear [17]. However, another study found no association between parenting styles and dental anxiety of children [18]. With limited evidence gleaned from very few studies, the association between parenting styles and children's DFA remains ambiguous.

In addition, a family dynamics model revealed that birth order could influence one's personality and behavior [19]. It has been reported that children's birth order partially determines their ability to cope with stresses in medical situations [20]. In the dental setting, only born children and first-born children were found to have a higher clinical situational DFA and were less cooperative than others $[21,22]$. A study involving children of various age showed that more children reported to have DFA if their siblings reported DFA [23]. However, no association was found between children's DFA and the number of children in their families in another study [24]. The current evidence concerning how birth order and presence of siblings are associated with children's DFA remains scarce and inconsistent findings have been reported.

In view of the currently insufficient and contradictory evidence, this study aimed to investigate the association between children's DFA and a variety of family related factors, namely parents' DFA, parenting styles, family structure (single-parent or nuclear family), and presence of siblings.

\section{Methods \\ Sample size calculation}

The sample size was calculated by using G*Power version 3.1.9.2. Targeting a statistical power of 0.9 and a significant level of 0.05 and estimating $13.5 \%$ children have DFA [25], 373 subjects are needed to detect an effect size of 0.5 .

\section{Participant recruitment}

The protocol of this study was reviewed by the Institutional Review Board (IRB) of the University of Hong Kong/Hospital Authority Hong Kong West Cluster. An ethical approval was obtained (\#UW16-130).

A list of government-funded elementary schools was retrieved from the official website of the Education Bureau, Hong Kong Special Administrative Region (http://www.edb.gov.hk). Among a total of 454 schools, 5 were randomly selected and approached. Three out of the 5 elementary schools participated. Child-mother-father triads were recruited. The inclusion criteria were: (i) the school was a government-funded, co-educational school (i.e. mixed-sex school); (ii) the child was enrolled in Primary 4-6 of a participating school; (iii) the child was 9-13 years old; and (iv) the child and his/her both parents were literate and were able to complete questionnaires themselves. Children with severe systemic diseases or physical or psychological disabilities were excluded. All eligible children in the participating schools were approached. Children with informed written consent from both parents were recruited.

\section{Questionnaires}

Each participating family was asked to complete a set of four questionnaires. The questionnaires were distributed via class teachers and were completed by the participants at home on a self-administered basis. Clear instructions were given to avoid confusion. All questionnaires were completed anonymously. Each participating family was identified with a code and their names were not disclosed. The questionnaires were pretested among 6 families with diverse background to ensure relevance and clarity. Completing the questionnaires took approximately $20 \mathrm{~min}$.

The first questionnaire, completed by parents, collected information on the child's demographic background (age, gender, and birth place), family socioeconomic status (family income, parents' education levels, parents' occupation, and housing condition), family 
structure (single-parent or nuclear family), presence of sibling, and the birth order of the child.

The second questionnaire was the Parental Authority Questionnaire (PAQ); a psychometric scale that assesses the authoritativeness, authoritarianism and permissiveness practiced by fathers and mothers, respectively, in rearing their children. This study used a short version comprising 20 items, which was adapted from the Buri's 30-item PAQ and showed adequate validity and internal consistency in children [26]. Test-retest reliability (the intraclass correlation) of Buri's PAQ were $0.77-0.92$ and internal consistency (Cronbach alpha) were 0.74-0.87 [27]. The validity was adequate; authoritarianism was inversely related to permissiveness (mother: $r=-0.38$; father: $r=-0.50$; all $p<0.0005$ ) and authoritativeness (mother: $r=-0.48$; father: $r=-0.52$; all $\mathrm{p}<0.0005$ ) and permissiveness was not significantly related to authoritativeness (mother: $r=0.07$; father: $r=0.12$; all $p>0.10$ ) [27]. The Chinese version of PAQ was adopted [28]. There were 7 items for authoritativeness, 7 for authoritarianism, and 6 for permissiveness. Responses to each item are made on a 5-point Likert scale, ranging from "strongly disagree" to "strongly agree". The total score for each parenting style was calculated by summing scores of items in the corresponding parenting style. Among the three parenting styles (authoritative, authoritarian and permissive), the one with the highest mean score was regarded as the dominant parenting style for that parent. The PAQ was completed by the child him/ herself, as instructed.

The third questionnaire was Corah Dental Anxiety Scale (CDAS) for measuring parents' DFA. CDAS has been widely used in research studies and its reliability, validity and usefulness have been documented [29]. The test-retest reliability (correlation coefficient) was 0.82 and the internal consistency (Kuder-Richardson Formula) was 0.86 . The validity was moderate as shown by the correlations between the dentists' ratings and the patients' test scores. The scale was later translated into Chinese [30]. CDAS contains 4 items, where respondents choose a score closest to their respective dental situations. The score ranged from 1 (not anxious) to 5 (extremely anxious). The total score for 4 items ranges from 4 to 20, with a higher score indicating a higher DFA level. The anxiety level was classified as "low" (scores below 9), "moderate" (scores from 9 to 12), "high" (scores from 13 to 14), and "severe" (scores from 15 to 20) [29].

The fourth questionnaire was the Children Fear Survey Schedule Dental Subscale (CFSS-DS), which was used to assess child's DFA. CFSS-DS consists of 15 items on various anxiety stimuli [31]. To each item, the response ranges 1-5, from "not afraid at all" to "very much afraid". The total score ranges from 15 to 75 . Children with a total CFSS-DS score below 32 are considered non-fearful; $32-39$ is defined as moderate fearful; $>39$ is defined as fearful [31]. CFSS-DS is deemed one of the most commonly used psychological scales for children. A Chinese version of CFSS-DS [32] was used in this study and was completed by the child him/herself. The test-retest reliability (intraclass correlation) of CFSS-DS was 0.71 and the internal consistency (Cronbach's alpha) was 0.85 [33]. The validity was good; higher mean CFSS-DS scores were found in children who were defined as uncooperative by using the Frankl Scale (standardized mean difference $=1.15 ; p<0.01$ ) [33]. All scales used can be found in Additional file 1.

\section{Statistical analysis}

The data analysis was performed by using Statistical Package for Social Sciences (SPSS) version 23.0. Participants' socio-demographic profile and family related factors were described. Parametric and non-parametric tests were used for comparing means/medians, whereas Chi-square tests were used for comparing proportions. Multiple linear regression models were constructed to test the associations after controlling for possible confounders. The collinearity among independent variables has been tested. In order to avoid possible collinearity, "mother's education" and "father's education" were converted to "parental education", defined as education level of mother or father, whichever is lower. The same conversion applied to "parental occupation". After such conversions, collinearity was ruled out because all the values of tolerance were well above 0.2 . The stratified analysis by gender was also carried out to test the associations in boys and girls, respectively.

\section{Results}

Socio-demographic profile, family related factors and parenting styles

Among 881 eligible families approached, 405 participated and returned the questionnaires. The response rate was $46.0 \%$. Most (71.0\%) children were $10-11$ year-old, with some 9 year-olds and 12-13 year-olds (Table 1 ). There were 188 (46.7\%) boys and 215 (53.3\%) girls. Most $(90.3 \%)$ of them were born in Hong Kong. Around two-thirds $(62.7 \%)$ of mothers were in the age group of $35-44$ and two-thirds (60.7\%) of fathers were 45 or above. Two-thirds $(69.5 \%)$ of families had a moderate monthly income (HKD 10,000-39,999). Housing condition was classified into basic (tenement building, public permanent housing), moderate (home ownership scheme, village house, and dormitory) and good (owned or rent private housing estates). Around $61.5 \%$ lived in basic housing condition. The majority of mothers (74.3\%) and fathers (72.8\%) reported secondary school as their highest education level. Occupation is classified 
Table 1 Socio-demographic profiles of participants

\begin{tabular}{|c|c|c|c|}
\hline & & $\mathrm{n}$ & $\%$ \\
\hline \multicolumn{4}{|l|}{ Child's demographic } \\
\hline \multirow[t]{2}{*}{ Gender } & Male & 188 & 46.7 \\
\hline & Female & 215 & 53.3 \\
\hline \multirow[t]{3}{*}{ Age (years) } & 9 & 69 & 17.9 \\
\hline & $10-11$ & 274 & 71.0 \\
\hline & $12-13$ & 43 & 11.1 \\
\hline \multirow[t]{2}{*}{ Place of birth } & Hong Kong & 355 & 90.3 \\
\hline & Other places & 38 & 9.7 \\
\hline \multicolumn{4}{|l|}{ Parents' demographic } \\
\hline \multirow[t]{3}{*}{ Mother's age (years) } & 34 or below & 45 & 12.1 \\
\hline & $35-44$ & 234 & 62.7 \\
\hline & 45 or above & 94 & 25.2 \\
\hline \multirow[t]{3}{*}{ Father's age (years) } & 34 or below & 7 & 2.0 \\
\hline & $35-44$ & 131 & 37.3 \\
\hline & 45 or above & 213 & 60.7 \\
\hline \multicolumn{4}{|c|}{ Socio-economic status of the family } \\
\hline \multirow[t]{3}{*}{ Family monthly income ${ }^{a}$} & Low (<HKD10000) & 71 & 20.4 \\
\hline & Moderate (HKD10000-39999) & 242 & 69.5 \\
\hline & High ( $\geq$ HKD40000) & 35 & 10.1 \\
\hline \multirow[t]{3}{*}{ Housing condition $^{\mathrm{b}}$} & Basic & 236 & 61.5 \\
\hline & Moderate & 46 & 12.0 \\
\hline & Good & 102 & 26.6 \\
\hline \multirow[t]{3}{*}{ Mother's Education } & Elementary school or below & 33 & 8.7 \\
\hline & Secondary school & 281 & 74.3 \\
\hline & Tertiary education or above & 64 & 16.9 \\
\hline \multirow[t]{3}{*}{ Father's Education } & Elementary school or below & 39 & 11.0 \\
\hline & Secondary school & 257 & 72.8 \\
\hline & Tertiary education & 57 & 16.1 \\
\hline \multirow[t]{4}{*}{ Mother's Occupation ${ }^{c}$} & Managerial or professional & 25 & 6.4 \\
\hline & Clerical or skilled workers & 51 & 13.0 \\
\hline & Service or labours & 64 & 16.4 \\
\hline & Housewives & 251 & 64.2 \\
\hline \multirow[t]{4}{*}{ Father's Occupation ${ }^{c}$} & Managerial or professional & 56 & 20.2 \\
\hline & Clerical or skilled workers & 97 & 35.0 \\
\hline & Service or labours & 113 & 40.8 \\
\hline & Unemployed & 11 & 4.0 \\
\hline \multicolumn{2}{|l|}{ Total } & 405 & 100.0 \\
\hline
\end{tabular}

${ }^{a}$ Source: Wang LD-L, Lam WWT, Fielding R. 2016. Hong Kong Chinese parental attitudes towards vaccination and associated socio-demographic disparities. Vaccine. 34:1426-1429

bHousing condition was classified into basic (tenement building, public permanent housing), moderate (home ownership scheme, village house, and dormitory) and good (owned or rent private housing estates)

'Occupation is classified into managerial or professional (managers and administrators, professionals, self-employed), clerical or skilled workers (associate professionals, clerical support workers), service or labours (sales, unskilled laborers, service industry) and housewives/unemployed into managerial or professional (managers and administrators, professionals, self-employed), clerical or skilled workers (associate professionals, clerical support workers), service or labours (sales, unskilled laborers, service industry) and housewives/unemployed. Two-thirds (64.2\%) of mothers were housewives. Two-thirds $(40.8 \%)$ of fathers were in the industry of "service or labours".

The majority $(91.5 \%)$ of children were from nuclear families. Most $(70.3 \%)$ children had siblings and more than half $(55.9 \%)$ were the first child in the family. Among the three parenting styles, both parents scored the highest in authoritativeness. The means (SD) were $3.6(0.8)$ and $3.6(0.9)$ for mothers and for fathers respectively. This was followed by "authoritarian", for which the means (SD) were $3.1(0.8)$ and $3.0(0.9)$ for mothers and fathers respectively. The scores were the lowest in permissiveness, with a mean (SD) of $2.6(0.8)$ and $2.8(0.9)$ for mothers and fathers respectively. "Authoritative" was identified as the dominant parenting style for 68.6 and $72.1 \%$ mothers and fathers respectively; while $25.0 \%$ mothers and $18.0 \%$ fathers practiced authoritarian parenting. Only $6.4 \%$ mothers and $9.9 \%$ fathers were permissive.

\section{Dental fear and anxiety (DFA) of child and parents}

Table 2 shows children's responses to possible fearful events related to dental practice. Items that over $20 \%$ children felt "very much afraid" or "pretty much afraid" were "the dentist drilling" (32.1\%), "the sight of dentist drilling" (24.3\%), "having a stranger touch you" (23.6\%), "hearing drilling sound" (22.5\%) and "injection" (20.6\%). As for their DFA level, $66.9 \%$ of the children were considered non-fearful, $15.3 \%$ were moderate and $17.8 \%$ were fearful. The mean (SD) total CFSS-DS score was 29.1 (11.0).

The DFA level of 43.4, 42.1, 11.6 and 2.8\% mothers was considered low, moderate, high and severe respectively. As for fathers' DFA level, 54.7, 37.0, 6.6 and 1.7\% were considered low, moderate, high and severe respectively. The means (SD) total CDAS score of mothers and fathers were 9.2 (3.0) and 8.2 (2.9) respectively.

\section{Family related factors and children's DFA}

No significant difference was found in children's DFA among all socio-economic subgroups (all $p>0.05$ ). Table 3 shows the results of bivariate analysis between each family related factor and children's DFA. Parental DFA and parenting styles of both parents were not associated with children's DFA (all p > 0.05). Children having siblings tended to report DFA, as compared with single child $(37.0 \%$ vs. $24.1 \%$; $p=0.034)$. They also had a higher CFSS-DS score (29.9 vs. $27.4 ; p=0.025)$. No significant 
Table 2 Children's dental fear and anxiety (DFA)

\begin{tabular}{|c|c|c|c|c|c|}
\hline & $\begin{array}{l}\text { Not afraid } \\
\text { at all }\end{array}$ & Very little fear & Moderate sfear & Pretty much afraid & $\begin{array}{l}\text { Very much } \\
\text { afraid }\end{array}$ \\
\hline Events/possible triggers & \multicolumn{5}{|c|}{ n (\%) } \\
\hline Dentists & $187(47.3)$ & $147(37.2)$ & $27(6.8)$ & $12(3.0)$ & $22(5.6)$ \\
\hline Doctors & $276(69.9)$ & $83(21.0)$ & $16(4.1)$ & $9(2.3)$ & $11(2.8)$ \\
\hline Injections & $122(31.0)$ & $139(35.3)$ & $52(13.2)$ & $26(6.6)$ & $55(14.0)$ \\
\hline Somebody examines your mouth & $265(67.3)$ & 93 (23.6) & $24(6.1)$ & $6(1.5)$ & $6(1.5)$ \\
\hline Having to open your mouth & $334(84.8)$ & $44(11.2)$ & $7(1.8)$ & $3(0.8)$ & $6(1.5)$ \\
\hline Having a stranger touch you & $100(25.3)$ & $120(30.4)$ & $82(20.8)$ & $37(9.4)$ & $56(14.2)$ \\
\hline Having somebody look at you & $180(45.8)$ & $107(27.2)$ & $61(15.5)$ & $22(5.6)$ & $23(5.9)$ \\
\hline Dentist drilling & $97(24.6)$ & $92(23.3)$ & $79(20.0)$ & $42(10.6)$ & $85(21.5)$ \\
\hline Sight of dentist drilling & $168(43.0)$ & $76(19.4)$ & $52(13.3)$ & $36(9.2)$ & $59(15.1)$ \\
\hline Hearing drilling sound & 155 (39.6) & $92(23.5)$ & $56(14.3)$ & $30(7.7)$ & $58(14.8)$ \\
\hline Putting instruments in mouth & $172(43.8)$ & $102(26.0)$ & $46(11.7)$ & $25(6.4)$ & $48(12.2)$ \\
\hline Choking & $163(42.0)$ & $116(29.9)$ & $58(14.9)$ & $22(5.7)$ & $29(7.5)$ \\
\hline Having to go to the hospital & $185(47.4)$ & $103(26.4)$ & 53 (13.6) & $18(4.6)$ & $31(7.9)$ \\
\hline People in white uniform & $302(77.0)$ & $56(14.3)$ & $15(3.8)$ & $8(2.0)$ & $11(2.8)$ \\
\hline Having the dentist clean your teeth & $271(69.0)$ & 77 (19.6) & $19(4.8)$ & $11(2.8)$ & $15(3.8)$ \\
\hline Mean (SD) of total CFSS-DS score & & & $29.1(11.0)$ & & \\
\hline Range of total CFSS-DS score & & & $15.0-66.0$ & & \\
\hline Possible range of the scale & & & $15.0-75.0$ & & \\
\hline \multirow[t]{3}{*}{ Level of DFA } & \multirow{2}{*}{\multicolumn{2}{|c|}{$\begin{array}{c}\text { Non-fearful } \\
\text { CFSS-DS score }<32\end{array}$}} & $\begin{array}{c}\text { Moderate fear } \\
\text { CFSS-DS score 32-39 }\end{array}$ & \multicolumn{2}{|c|}{$\begin{array}{c}\text { Fearful } \\
\text { CFSS-DS score }>39\end{array}$} \\
\hline & & & n (\%) & & \\
\hline & \multicolumn{2}{|c|}{$245(66.9)$} & $56(15.3)$ & \multicolumn{2}{|c|}{$65(17.8)$} \\
\hline
\end{tabular}

difference was found in DFA scores of those who were first child in the family and others.

When multivariate analysis (linear regression) was conducted (Table 4), children from single-parent families were found with lower CFSS-DS score as compared with children from nuclear families $(\beta=-9.177 ; p=0.029)$. When stratified analysis was carried out for boys and girls separately (Model 2 and Model 3), it was found that (i) boys who had siblings had significantly higher DFA in contrast to those without siblings $(\beta=7.130 ; p=0.010)$; (ii) boys whose family had a basic housing condition reported significantly lower DFA as compared with those under a good housing condition $(\beta=-7.752 ; p=0.006)$; and (iii) girls from single-parent families had lower DFA score as compared with girls from nuclear families $(\beta=-13.933 ; p=0.015)$.

\section{Discussion}

This study explored the possible associations between children's DFA and a variety of family related factors. The results showed that DFA was quite common an issue reported by around one third (33.1\%) of children. In comparison with children from nuclear families, children from single-parent families had lower DFA score. Subgroup analysis showed that boys' DFA was associated with "having siblings", whereas girls' DFA was lower when they were from "single-parent families". Children's DFA was however not associated with parents' DFA or parental styles.

Invasive procedures and dental pain were often reported as the most important causes of dental anxiety $[5,14]$. Similarly, teenagers participating in this study tended to relate their DFA to injection and drilling; the latter also extended to stimuli (sound and sight) associated with drilling. It is worth noting that "having a stranger touch you" also appeared as a major fearful situation for the respondents. Our finding is somewhat in line with that of a previous study, in which "having a stranger touch you" was identified as the highest-ranked cause for dental fear, followed by "injection" and "choking" [34]. Although being touched by a stranger in the clinical scenario may not be unexpected and stressful to adult patients, it may impose considerable stress on adolescents. This highlights the importance of building rapport and trust with adolescent patient before starting any dental examination and treatment. 
Table 3 Family related factors and Children's DFA

\begin{tabular}{|c|c|c|c|c|}
\hline & No fear (CFSS-DS <32) & Moderate fear (CFSS-DS 32-39) & Severe fear (CFSS-DS >39) & Total CFSS-DS score \\
\hline & & n (\%) & & Mean (SD) \\
\hline Parental dental fear & & & & \\
\hline CDAS scale of mother & & & & \\
\hline Low anxiety & $109(69.4)$ & $27(17.2)$ & $21(13.4)$ & $27.90(10.02)$ \\
\hline Moderate anxiety & $90(63.8)$ & $20(14.2)$ & $31(22.0)$ & $29.72(11.98)$ \\
\hline High/sever anxiety & $35(66.0)$ & $8(15.1)$ & $10(18.9)$ & $30.49(10.62)$ \\
\hline & & $P=0.411$ & & $P=0.277$ \\
\hline CDAS scale of father & & & & \\
\hline Low anxiety & $128(70.3)$ & $21(11.5)$ & $33(18.1)$ & $28.42(11.75)$ \\
\hline Moderate anxiety & $78(62.4)$ & $22(17.6)$ & $25(20.0)$ & $29.80(10.63)$ \\
\hline High/sever anxiety & $13(56.5)$ & $7(30.4)$ & $3(13.0)$ & $31.39(11.10)$ \\
\hline & & $P=0.141$ & & $P=0.111$ \\
\hline Parenting style & & & & \\
\hline Mother dominant style & & & & \\
\hline Authoritative & $167(68.2)$ & $33(13.5)$ & $45(18.4)$ & $28.91(10.75)$ \\
\hline Authoritarian & $58(63.7)$ & $18(19.8)$ & $15(16.5)$ & $29.54(11.64)$ \\
\hline Permissive & $16(69.6)$ & $2(8.7)$ & $5(21.7)$ & $28.87(13.23)$ \\
\hline & & $P=0.593$ & & $P=0.853$ \\
\hline Father dominant style & & & & \\
\hline Authoritative & $164(66.9)$ & 39 (15.9) & $42(17.1)$ & $28.56(10.63)$ \\
\hline Authoritarian & $42(64.6)$ & $10(15.4)$ & $13(20.0)$ & $30.52(11.74)$ \\
\hline Permissive & $24(70.6)$ & $4(11.8)$ & $6(17.6)$ & $29.54(13.22)$ \\
\hline & & $P=0.952$ & & $P=0.531$ \\
\hline Family characteristics & & & & \\
\hline Family structure & & & & \\
\hline Nuclear family & $212(66.3)$ & $51(15.9)$ & $57(17.8)$ & $29.1(11.1)$ \\
\hline Single-parent family & $23(76.7)$ & $3(10.0)$ & $4(13.3)$ & $26.3(9.6)$ \\
\hline & & $p=0.500$ & & $p=0.167$ \\
\hline Having siblings & & & & \\
\hline Yes & $158(62.9)$ & 45 (17.9) & $48(19.1)$ & 29.9 (11.1) \\
\hline No & $85(75.9)$ & $10(8.9)$ & $17(15.2)$ & $27.4(10.8)$ \\
\hline & & $p=0.034^{*}$ & & $p=0.025^{*}$ \\
\hline First child & & & & \\
\hline Yes & $141(70.5)$ & $22(11.0)$ & $37(18.5)$ & $28.8(11.4)$ \\
\hline No & $98(62.8)$ & 31 (19.9) & $27(17.3)$ & $29.4(10.4)$ \\
\hline & & $p=0.065$ & & $p=0.280$ \\
\hline
\end{tabular}

$p$ values for categorical outcomes were obtained from the Chi-square test. $p$ values for continuous outcomes were obtained from the non-parametric test (MannWhitney $\mathrm{U}$ test or Kruskal-Wallis test)

*Significant difference

It was often speculated that parental DFA and parenting styles are associated with children's DFA. Such association was supported by a studies conducted in the US [12] and was however absent in our study sample. It is worth noting that our study focused on a slightly older age group as compared with the
American study. There is a notion that older children's perception of dental treatment is more influenced by their actual dental experience such as painful procedure and professional's behaviors [17]. Fear toward unknown appears to be predominant during early childhood, but fears are usually linked to 
Table 4 Determinants of DFA in children (CFSS-DS score)

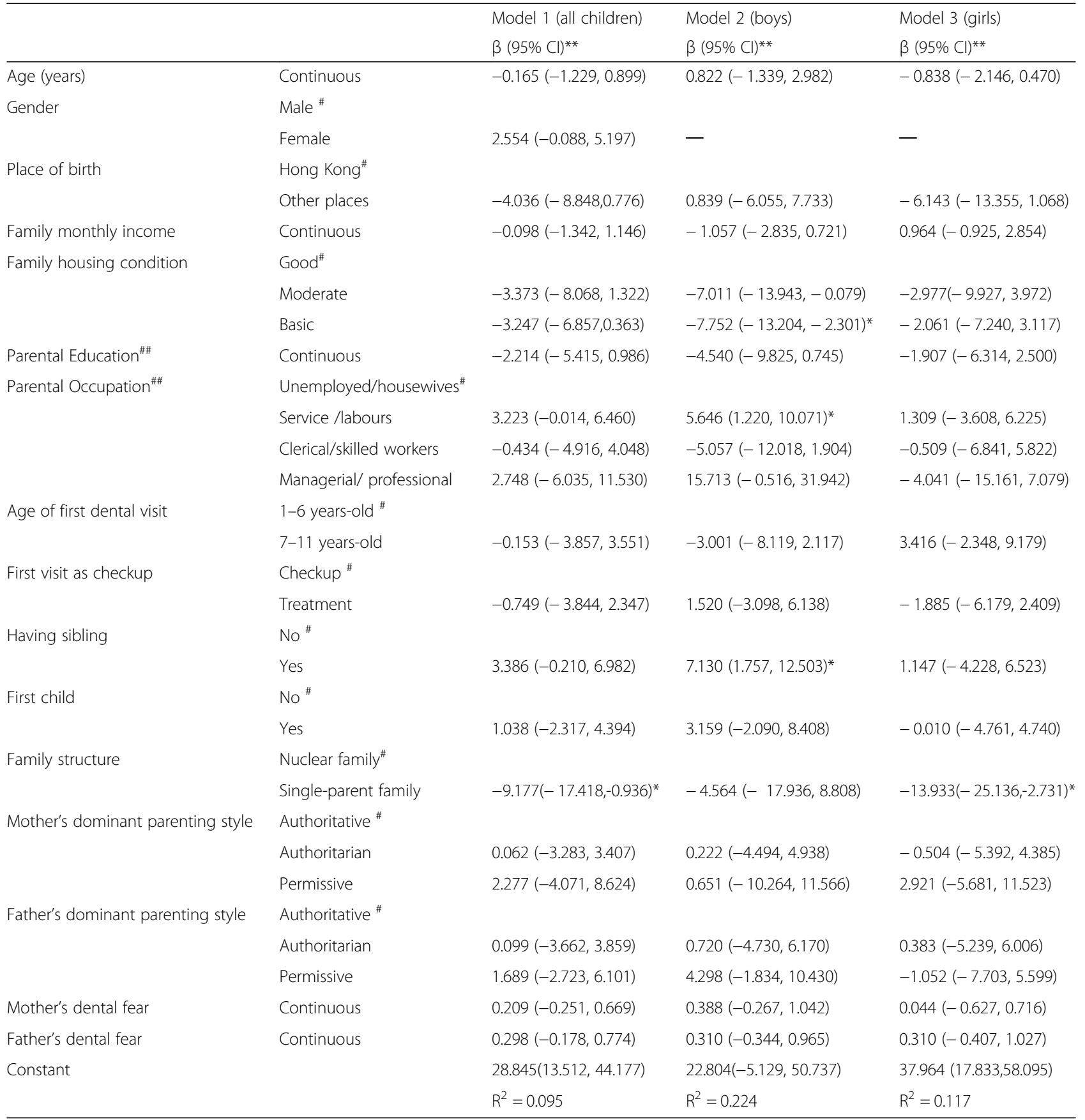

The results were obtained through multiple linear regressions using total CFSS-DS score of all children, CFSS-DS score of boys, and CFSS-DS score of girls as a dependent variable respectively. Independent variables are as above

*Significant difference between/among subgroups

${ }^{*} \mathrm{Cl}$ : confidence interval

\#Reference group

\#\#Parental education was defined as mother's or father's education, whichever is lower. The same conversion applied to "parental occupation"

body injures including various situations encounter in dental setting by 9 years of age [35]. A review also indicated that the relationship between parental and child' dental fear was obvious in children under 8 years old [10]. It is possible that parental DFA is not a direct factor to influence child's DFA when the child reached adolescence.

The finding that children in single-parent families reported less DFA is in congruence with a previous study [18] but contradict some others [36, 37]. In single-parent 
families, children may become more independent and are more likely to grow maturity and resilience [38]. Given these characteristics, they may cope better with the challenges and stressful situations, such as dental visit. Also, children in single-parent families may receive more attention from other caregivers, such as grandparents. This might also play a role in their growth and development. For instance, grandfathers were identified as an important figure who can affect the emotional transmission of dental fear among family members [13].

Given the gender difference in psychological development and socialization, stratified analysis was performed for boys and girls respectively. It was found that among boys, the impact of having sibling(s) was evident; those with sibling(s) reported significantly higher DFA. There is a notion that only-born children tend to internalize parents' expectations, turn predominantly mature, have higher self-esteem, and grow adult behavior due to their enhanced time interacting with adults [39]. On the other hand, there was an alternative theory describing personality of single-born children as more self-centered, demanding, shy, dependent and moody [40]. While the former lends support to our findings, the latter points to the possibility of higher DFA in single children, which was a finding of some other studies [21, 22]. There were also research studies suggesting no difference in the personalities of single child and their peers with siblings when judged by parents, teachers, and themselves [41]. Apart from personality traits, siblings' past dental experience and their positive or negative modeling might play an important role in shaping children's perception of dental care. The analysis for girls showed that living in a single family indicated a lower level of DFA, as compared with those in nuclear families. It is believed that girls are more adult-oriented [42]; therefore they may be more affected by parental factors and less by their siblings.

The findings of this study could be better interpreted by taking into consideration the methodological strengthens and limitations. Data were collected from a relatively large sample with diverse backgrounds. Well-established and validated psychometric scales were used to measure parenting styles and the DFA of children and their parents. For determining the parenting styles, different scales are available and can be completed by parents or children. Since parents may tend to give socially desirable answers and their perceptions may not truly reflect the reality, children's response is preferable. Although some items may seem abstract, reliable answers could be obtained from adolescents through proper wording of the questions. This study is cross-sectional in nature. Therefore, no temporal relationship can be established and our findings could only suggest associations but not causation. The sample of this study was drawn from children in Hong Kong. Therefore, findings of this study cannot be directly extrapolated to other populations, although some useful implications can be drawn especially for populations of similar cultures and social context. Although the regression models suggested the impact of familial factors on children's DFA, the $\mathrm{R}^{2}$ were low and the models only explained $9.5,22.4$, and $11.7 \%$ of the variance in DFA of all subjects, boys, and girls, respectively. This supports the notion that DFA is a complex phenomenon, in which many other factors, such as child's personality traits [43], past dental experiences [44], other life incidents/events [45], were involved.

To sum up, several implications can be derived from the findings of this study. The commonly neglected factors (e.g. "having a stranger touch you") that trigger DFA in children implies that dental personnel could consider spending some time wherever possible to establish trust with paediatric patients before proceeding to dental procedures. Previous research revolved around parents' DFA and consequently negative modeling on children. Our findings however suggest that the impact of family on the development of children's DFA is not as straightforward as previously speculated. In contrast to the assumption held by many people, our results showed that children's DFA is not associated with parents' DFA and parenting style. Instead, family structure (nuclear/single-parent family) and presence of siblings plays a significant role in children's DFA. To prevent and intercept DFA among children, it may be important to redirect the attention from parental influence to possible negative influence of siblings. Although children from nuclear family might benefit from such healthy family environment in many aspects of their personal growth, they are more likely to have DFA. Parents and clinicians are advised to be more sensitive to the signs of DFA in these children and make necessary efforts to prepare them for dental visits.

\section{Conclusions}

Family structure (nuclear or single-parent family) and presence of siblings are significant determinants for children's DFA. Parental DFA and parenting style do not affect children's DFA significantly.

\section{Additional file}

Additional file 1: Scales used (PDF $265 \mathrm{~kb}$ )

Abbreviations

CDAS: Corah Dental Anxiety Scale; CFSS-DS: Fear Survey Schedule-Dental Subscale; DFA: Dental fear and anxiety; PAQ: Parent Authority Questionnaire; SPSS: Statistical Package for Social Sciences 


\section{Acknowledgements}

The following people have contributed significantly to the subject recruitment, preparation of questionnaires, data collection, and data handling: CHU Sin Po, KWOK Hoi Ching Venus, LAI Wing Tak, LEE Hor Ching, MOK Kar Po Carolle, NGAN Ming Chun, WONG Wing Lam, YIP Chun Kit and YU Chak Fai.

\section{Funding}

This study was financially supported by the Faculty of Dentistry, The University of Hong Kong. The funding body played no role in the design of the study and collection, analysis, and interpretation of the data and in writing the manuscript.

\section{Availability of data and materials}

The datasets used and/or analyzed during the current study are available from the corresponding author on reasonable request.

\section{Authors' contributions}

LW contributed to the data analysis and manuscript preparation. XG contributed to the design of the work and supervised the data collection, data analysis, manuscript preparation and critical revisions. Both authors have read and approved the final version of the manuscript submitted for publication.

\section{Ethics approval and consent to participate}

The protocol of this study was reviewed by the Institutional Review Board (IRB) of the University of Hong Kong/Hospital Authority Hong Kong West Cluster. An ethical approval was obtained (\#UW16-130). Informed written consent was taken from both parents of each participating child.

\section{Competing interests}

The authors declare that they have no competing interests.

\section{Publisher's Note}

Springer Nature remains neutral with regard to jurisdictional claims in published maps and institutional affiliations.

\section{Author details}

'Department of Dentistry, Key Laboratory of Oral Diseases of Gansu Province, Northwest University for Nationalities, Lanzhou, China. ${ }^{2}$ Dental Public Health, Faculty of Dentistry, The University of Hong Kong, 3rd Floor, Prince Philip Dental Hospital, 34 Hospital Road, Sai Ying Pun, Hong Kong.

Received: 25 January 2018 Accepted: 22 May 2018

Published online: 04 June 2018

\section{References}

1. Klingberg G, Broberg AG. Dental fear/anxiety and dental behaviour management problems in children and adolescents: a review of prevalence and concomitant psychological factors. Int J Paediatr Dent. 2007;17:391-406

2. Chhabra N, Chhabra A, Walia G. Prevalence of dental anxiety and fear among five to ten year old children: a behaviour based cross sectional study. Minerva Stomatol. 2012;61:83-9.

3. Baier K, Milgrom P, Russell S, Mancl L, Yoshida T. Children's fear and behavior in private pediatric dentistry practices. Pediatr Dent. 2004;26: $316-21$

4. Gatchel RJ. The prevalence of dental fear and avoidance: expanded adult and recent adolescent surveys. J Am Dent Assoc (1939). 1989:118:591-3.

5. Gao X, Hamzah SH, Yiu CK, McGrath C, King NM. Dental fear and anxiety in children and adolescents: qualitative study using YouTube. J Med Internet Res. 2013;15:e29.

6. Crocombe LA, Broadbent JM, Thomson WM, Brennan DS, Slade GD, Poulton R. Dental visiting trajectory patterns and their antecedents. J Public Health Dent. 2011;71:23-31.

7. Milgrom P, Weinstein P. Dental fears in general practice: new guidelines for assessment and treatment. Int Dent J. 1993;43:288-93.

8. Rachman S. The conditioning theory of fear-acquisition: a critical examination. Behav Res Ther. 1977;15:375-87.

9. Newman BM. Development through life: a psychosocial approach (6th ed.) Pacific Grove, Calif: Brooks/Cole Pub. Co. 1995
10. Themessl-Huber M, Freeman R, Humphris G, MacGillivray S, Trezi N. Empirical evidence of the relationship between parental and child dental fear: a structured review and meta-analysis. Int J Paediatr Dent. 2010;20:83-101.

11. Boynes SG, Abdulwahab M, Kershner E, Mickens F, Riley A. Analysis of parental factors and parent-child communication with pediatric patients referred for nitrous oxide administration in a rural community health center setting. Oral Biol Dent. 2014;2:10.

12. Majstorovic M, Morse DE, Do D, Lim L, Herman NG, Moursi AM. Indicators of dental anxiety in children just prior to treatment. J Clin Pediatr Dent. 2014 39:12-7.

13. Lara A, Crego A, Romero-Maroto M. Emotional contagion of dental fear to children: the fathers' mediating role in parental transfer of fear. Int J Paediatr Dent. 2012:22:324-30

14. Olak J, Saag M, Honkala S, Nommela R, Runnel R, Honkala E, Karjalainen S. Children's dental fear in relation to dental health and parental dental fear. Stomatologija. 2013;15:26-31.

15. Burlaka V. Externalizing behaviors of Ukrainian children: the role of parenting. Child Abuse Negl. 2016;54:23-32.

16. Baumrind D. Current patterns of parental authority. Dev Psychol. 1971:4:1-103.

17. Ten Berge M, Veerkamp JS, Hoogstraten J, Prins PJM. Childhood dental fear in relation to parental child-rearing attitudes. Psy Report. 2003;92:43-50.

18. Krikken JB, Vanwijk AJ, Tencate JM, Veerkamp JS. Child dental anxiety, parental rearing style and dental history reported by parents. Eur J Paediatr Dent. 2013;14:258-62.

19. Sulloway FJ. Birth-order, sibling competition, and human behavior. In: Holcomb HR, editor. Conceptual challenges in evolutionary psychology: innovative research strategies. 3rd ed. Dordrecht, the Netherlands: Kluwer Academic; 2001

20. Gould SJ. Dolly's fashion and louis's passion. (implications of the current fascination with the genetic sciences and its use in popular culture to explain moral and behavioral phenomena: cloned sheep and behavior of first-born judges who condemned louis xiv). Nat Hist. 1997;106:18.

21. Aminabadi NA, Sohrabi A, Erfanparast LK, Oskouei SG, Ajami BA. Can birth order affect temperament, anxiety and behavior in 5 to 7 -year-old children in the dental setting? J Contemp Dent Pract. 2011;12:225-31.

22. Ghaderi F, Fijan S, Hamedani S. How do children behave regarding their birth order in dental setting? J dent (Shiraz,Iran). 2015;16:329-34.

23. Rantavuori K, Tolvanen M, Hausen $H$, Lahti S, Seppä L. Factors associated with different measures of dental fear among children at different ages. J Dent Child (Chic). 2009;76:13-9.

24. Peretz B, Nazarian Y, Bimstein E. Dental anxiety in a students' paediatric dental clinic: children, parents and students. Int J Paediatr Dent. 2004;14: 192-8.

25. Chellappah NK, Vignehsa H, Milgrom P, Lo GL. Prevalence of dental anxiety and fear in children in Singapore. Community Dent Oral Epidemiol. 1990;18:269-71.

26. Alkharusi H, Aldhafri S, Kazem A, Alzubiadi A, Al-Bahrani M. Development and validation of a short version of the parental authority questionnaire Social Behavior And Personality. 2011:39:1193-208.

27. Buri JR. Parental authority questionnaire. J Pers Assess. 1991;57:110-9.

28. Zhou YJ, Liang BY, Cai Y. Chinese revision of Buri's parental authority questionnaire. Chin J Clin Psych. 2010;18:8-10.

29. Corah NL. Development of a dental anxiety scale. J Dent Res. 1969:48:596.

30. Guo B, Liu J, Yang F, Xie SJ, Que KH, Zhang Q. The prevalence of dental anxiety in the aged people. International journal of stomatology. 2007;34: $162-4$.

31. Cuthbert MI. Melamed BG. A screening device: children at risk for dental fears and management problems. ASDC J Dent Child. 1982;49:432-6.

32. Lu JX, Yu DS, Luo W, Xiao XF, Zhao W. Development of Chinese version of children's fear survey schedule-dental subscale, Zhonghua kouqiang yixue zazhi $=$ Chinese journal of stomatology 2011; 46: 218-221.

33. Ma L, Wang M, Jing Q, Zhao J, Wan K, Xu Q. Reliability and validity of the chinese version of the children's fear survey schedule-dental subscale. Int $J$ Paediatr Dent 2015:25:110-6.

34. Raadal M, Milgrom P, Weinstein P, Mancl L, Cauce AM. The prevalence of dental anxiety in children from low-income families and its relationship to personality traits. J Dent Res. 1995;74:1439-43.

35. Chapman HR, Kirby-Turner NC. Dental fear in children-a proposed model. Br Dent J. 1999;187:408-12.

36. Gustafsson A. Dental behaviour management problems among children and adolescents-a matter of understanding? Studies on dental fear, 
personal characteristics and psychosocial concomitants Swed Dent J Suppl 2010:2 p preceding 1-46.

37. Suprabha BS, Rao A, Choudhary S, Shenoy R. Child dental fear and behavior: the role of environmental factors in a hospital cohort. J Indian Soc Pedod Prev Dent. 2011;29:95-101.

38. Spagnola M, Fiese BH. Family routines and rituals. Infants \& Young Children. 2007;20:284-99.

39. Shen J, Yuan BJ. Moral values of only and sibling children in mainland China. The J Psychol. 1999;133:115-24.

40. Bögels SM, Brechman-Toussaint ML. Family issues in child anxiety: attachment, family functioning, parental rearing and beliefs. Clin Psychol Rev. 2006;26:834-56.

41. Falbo T, Poston DL Jr. The academic, personality, and physical outcomes of only children in China. Child Dev. 1993;64:18-35.

42. Crombie G. Gender differences: implications for social skills assessment and training. J Clin Child Psychol. 1988;17:116-20.

43. Halonen H, Salo T, Hakko H, Rasanen P. Association of dental anxiety to personality traits in a general population sample of finnish university students. Acta Odontol Scand. 2012;70:96-100.

44. Lee CY, Chang YY, Huang ST. The clinically related predictors of dental fear in taiwanese children. Int J Paediatr Dent. 2008;18:415-22.

45. Hagqvist O, Tolvanen M, Rantavuori K, Karlsson L, Karlsson H, Lahti S. Dental fear and previous childhood traumatic experiences, life events, and parental bonding. Eur J Oral Sci. 2015;123:96-101.

Ready to submit your research? Choose BMC and benefit from:

- fast, convenient online submission

- thorough peer review by experienced researchers in your field

- rapid publication on acceptance

- support for research data, including large and complex data types

- gold Open Access which fosters wider collaboration and increased citations

- maximum visibility for your research: over $100 \mathrm{M}$ website views per year

At BMC, research is always in progress.

Learn more biomedcentral.com/submissions 